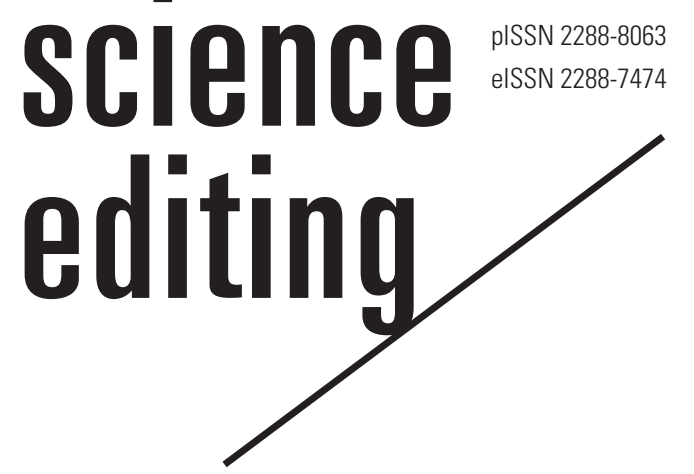

\title{
Internal affairs: the fate of authors from the University of the Philippines accused of plagiarism, 1990s to 2010s
}

\author{
Miguel Paolo P. Reyes, Joel F. Ariate Jr. \\ Third World Studies Center, College of Social Sciences and Philosophy, University of the Philippines Diliman, Quezon City, The \\ Philippines
}

\begin{abstract}
Purpose: This study centers on 25 cases of plagiarism in scientific publications committed by faculty members and students of the University of the Philippines and dealt with by eight of the university's academic publishers.

Methods: We focus on the publishers' responses to these cases, details of which we obtained from various sources, vis-à-vis the University of the Philippines' policies on plagiarism.

Results: The responses to plagiarism were found to vary, at times seemingly arbitrarily, but tended toward protecting the identities or details of the accused, unless the case became publicized.

Conclusion: Such maintenance of confidentiality is inimical to the fulfillment of academic publishers' duties to the rest of the academic community. We herein suggest policies to address the identified deficits.

Keywords

Confidentiality; Philippine publishers; Plagiarism; University of the Philippines
\end{abstract}

Received: June 19, 2019 Accepted: July 15, 2019

Correspondence to

Miguel Paolo P. Reyes

mpreyes3@up.edu.ph

ORCID

Miguel Paolo P. Reyes

https://orcid.org/0000-0003-2496-6785

Joel F. Ariate Jr.

https://orcid.org/0000-0001-8120-0255

\section{Introduction}

Reputable academic or scholarly publishers necessarily have stringent policies on plagiarism. Without plagiarism checks, a scholarly publisher risks publishing texts that not only fail to follow accepted norms of attribution, but also potentially pollute or distort scientific literature, making the previously published (perhaps even refuted or falsified) seem novel, or obscuring the actual progression of scholarly inquiry on a particular matter. From a legal perspective, plagiarism per se is not a crime in any jurisdiction, but plagiarized content might be copyrighted. In short, checking submissions for plagiarism is in line with the gatekeeping functions of academic editors [1]. 
Currently, there are no national guidelines on dealing with plagiarism for academic publishers in the Philippines, or even for the University of the Philippines (UP), the country's national university and the institution focused on here. While the numerous scholarly journals published by various UP units may have their own internal counter-plagiarism processes and measures, few such processes and measures are accessible via the university's online journal portals (e.g., http:// www.journals.upd.edu.ph/, https://ovcre.uplb.edu.ph/journals-uplb/, and http://ojs.upmin.edu.ph/) or other UP journal websites. Exceptions include the Philippine Journal of Social Development, whose publicly accessible 2016 editorial and publication policies include a definition of and guidelines on plagiarism [2], and the shared 2009 "Journal policy on research misconduct" of Humanities Diliman, Science Diliman, and Social Science Diliman, which has been included in openaccess issues of these journals since 2016 [3]. Indeed, participants in one of the few recent nationwide gatherings of journal editors in the country did not consider plagiarism to be a major concern [4].

Besides being little discussed locally as a policy matter by academic publishers, plagiarism in the Philippines in any context is still largely understudied. Extant work generally focuses on plagiarism by students, tackling pedagogical interventions [5], or plagiarism in relation to legal issues [6]. Studies discussing scholarly publishing in the Philippines tend to focus on the factors constraining publishers from matching the quality and quantity of output of their Western counterparts, sustainability concerns, and other publishing challenges [7-9]. No existing publication has thus far intensively engaged with the subject of plagiarism by faculty members of any Philippine educational institution.

Given the lack of standardized rules and dearth of scholarship, this study is an initial attempt to analyze the responses of academic publishers in the Philippines to plagiarism, with the aim of using these responses to suggest counter-plagiarism policies for similarly situated academic editors. Specifically, this study looks at cases wherein both the publisher and the author(s) accused of plagiarism are or were members of UP's academic community (i.e., as a faculty member or student), with the presupposition that such cases are particularly difficult to address because they involve internal policing. Focusing on such cases thus allows us to examine the nexus between the preservation of institutional reputations or academic integrity, and the scholarly gatekeeping function of academic editors.

\section{Methods}

Data discussed in this paper were mainly gathered during two research projects, both of which aimed to analyze UP's responses to plagiarism, with one focusing on plagiarism by

Table 1. UP rules on confidentiality for records of student and faculty member cases

\begin{tabular}{|c|c|c|c|}
\hline & Period & Rules (year implemented) & Relevant text of provision \\
\hline \multirow[t]{2}{*}{ Students } & 1976-2014 & $\begin{array}{l}\text { Section } 24 \text { of the Rules and Regulations on Student ' } \\
\text { Conduct and Discipline }\end{array}$ & $\begin{array}{l}\text { "Original records pertaining to student discipline shall be under the custody } \\
\text { of the Vice Chancellor for Student Affairs. Such records are hereby de- } \\
\text { clared confidential and no person shall have access to the same for in- } \\
\text { spection or copying unless s/he is involved therein, or unless s/he has a } \\
\text { legal right which cannot be protected or vindicated without access to or } \\
\text { copying of such records." }\end{array}$ \\
\hline & 2014-present & $\begin{array}{l}\text { Section V.7. of the Code of Student Conduct of UP ' } \\
\text { Diliman (completed in 2012, adopted by other UP } \\
\text { constituent universities) }\end{array}$ & $\begin{array}{l}\text { "Original records pertaining to student discipline shall be under the custody } \\
\text { of the [Student Disciplinary Council] and/or the Dean. Such records are } \\
\text { hereby declared confidential and no person shall have access to the same } \\
\text { for inspection or copying unless s/he has a legal right which cannot be } \\
\text { protected or vindicated without access to or copying of such records, or } \\
\text { unless authorized in writing by the Chancellor." }\end{array}$ \\
\hline \multirow[t]{2}{*}{ Faculty } & 1961-present & $\begin{array}{l}\text { Article } 247 \text { of the Revised Code of the University of the ' } \\
\text { Philippines, as stated in Section 10.2.11 of the } 2003 \\
\text { University of the Philippines Diliman Faculty Manual } \\
\text { (adopted by other UP constituent universities) }\end{array}$ & $\begin{array}{l}\text { "No member of the faculty, officer, or employee shall publish or discuss pub- } \\
\text { licly charges or complaints against any other member of the faculty, offi- } \\
\text { cer, or employee concerning his/her official duties or his/her private life or } \\
\text { conduct." }\end{array}$ \\
\hline & 1963-present & $\begin{array}{l}\text { Section } 13 \text { of the Rules and Regulations on the Dis- ' } \\
\text { cipline of Faculty Members and Employees }\end{array}$ & $\begin{array}{l}\text { "All proceedings held before the [Hearing Committee] shall be set down in } \\
\text { writing by a competent stenographer and shall be confidential. Any disclo- } \\
\text { sure of matters related to the proceedings shall subject the offender to } \\
\text { disciplinary action." }\end{array}$ \\
\hline
\end{tabular}

UP, University of the Philippines. 


\section{science editing /}

faculty members throughout the UP System, which has eight constituent universities and 17 campuses across the Philippines, and the other on faculty and student plagiarism cases at UP Diliman, the System's largest university. For both projects, the main obstacles to data gathering were UP's strict rules on confidentiality in cases involving research malpractice or academic dishonesty, as previously stated in relevant publications $[10,11]$. These rules are listed in Table 1.

Despite these restrictions, we were able to identify a number of documented and verifiable cases of plagiarism by members of UP's academic community via nonconfidential university records (e.g., minutes of the meetings of the UP Board of Regents), key informant interviews, and online and print publications. UP Diliman's Office of the Chancellor authorized us to examine selected final and executory student case files of the defunct Student Disciplinary Tribunal. Regarding faculty case files, we wrote to relevant offices in all UP constituent universities requesting access to case decisions or resolutions, assuming that such are either beyond the level of charges or complaints mentioned in the "UP system code" or outside of the verbatim proceedings contemplated in the "Rules and regulations on the discipline of faculty members and employees"; few offices shared our interpretation, however, with only two granting access to preselected case files. Data gathering was primarily conducted between 2011 and 2015 . Cases identified after 2015 became known to us through chance encounters with details in published texts or our positions on the editorial staff of the publication involved. We identified 74 verifiable plagiarism cases-wherein at least a description of what was committed and how the case was handled may be obtained from authoritative sources-involving dozens of UP faculty members and students at UP Diliman, as well as a handful of students at other UP constituent universities, all occurring between 1936 and 2018. Of these cases, 34 are detailed in a 97-page confidential document we wrote titled "Final research report on academic and authorial integrity in University of the Philippines-Diliman," a copy of which was deposited with UP Diliman's Office of the Vice Chancellor for Research and Development.

A total of 25 of the 74 cases involved students and faculty members of the UP System who, during the time they were connected to UP, had their work published or considered for publication by a UP publisher (i.e., a unit, department, or college within UP with a publications program). The term "publication" here is broadly construed; included are dissertations, which are publicly accessible through various libraries and whose editors may be considered to be the dissertation adviser/committee members. Eight UP publishers, two of which are not based at UP Diliman, are involved in the cases discussed here.
We know the details of 18 of the cases because of our involvement with the publications that processed the works. We received information about one case from informants and an examination of the submission in question. The details of another case came to our attention via interviews with current and former university officials. A UP office gave us access to selected confidential documentation of one case, and we filed one of the other cases ourselves. Lastly, three cases are discussed in public records or publications.

Given that this study seeks to make case-based policy recommendations, we concentrate on publishers' responses to plagiarism in a work they had published or are considering for publication. We provide context by indicating the decade when the plagiarism was committed, whether the offense was discovered after a faculty member or student had already been separated from the institution or graduated, and if the accusation was made before or after a work's publication, thereby showing possible jurisdictional constraints on the actions of the publishers involved.

Through personal knowledge, social media, and websites such as online employment services, we attempted to track the post-response effects on the academic careers and scholarly credibility of the faculty members and students accused in the 25 cases. These effects served as a proxy for response effectiveness, assuming that the thrust of the response generally is punitive rather than rehabilitative. We initially assumed that those who receive the most severe penalties (e.g., termination/involuntary resignation or degree withdrawal) suffered the most in terms of loss in scholarly stature (here shown by the approximate number of years between the final case response and the resumption of an academic career). To test this assumption further, we also analyzed the post-response effects on UP faculty or students whose work containing plagiarism was published by non-UP publishers. Regarding those who did not resume their academic careers after committing plagiarism, we tracked their post-response publications, if any, and non-self-citations to see if their scholarly contributions continued to be valued.

\section{Results}

Table 2 summarizes the 25 plagiarism cases committed by UP faculty members or students and published by UP. We gave the cases numerical designations, with the order determined by the approximate date when the publisher initiated proceedings in response to plagiarism. We cannot mention the constituent university, publisher, or any similar identifying information because of UP's confidentiality rules. Besides confidential records, key informants, the text of the manuscripts or publications themselves, and our personal knowledge, other 


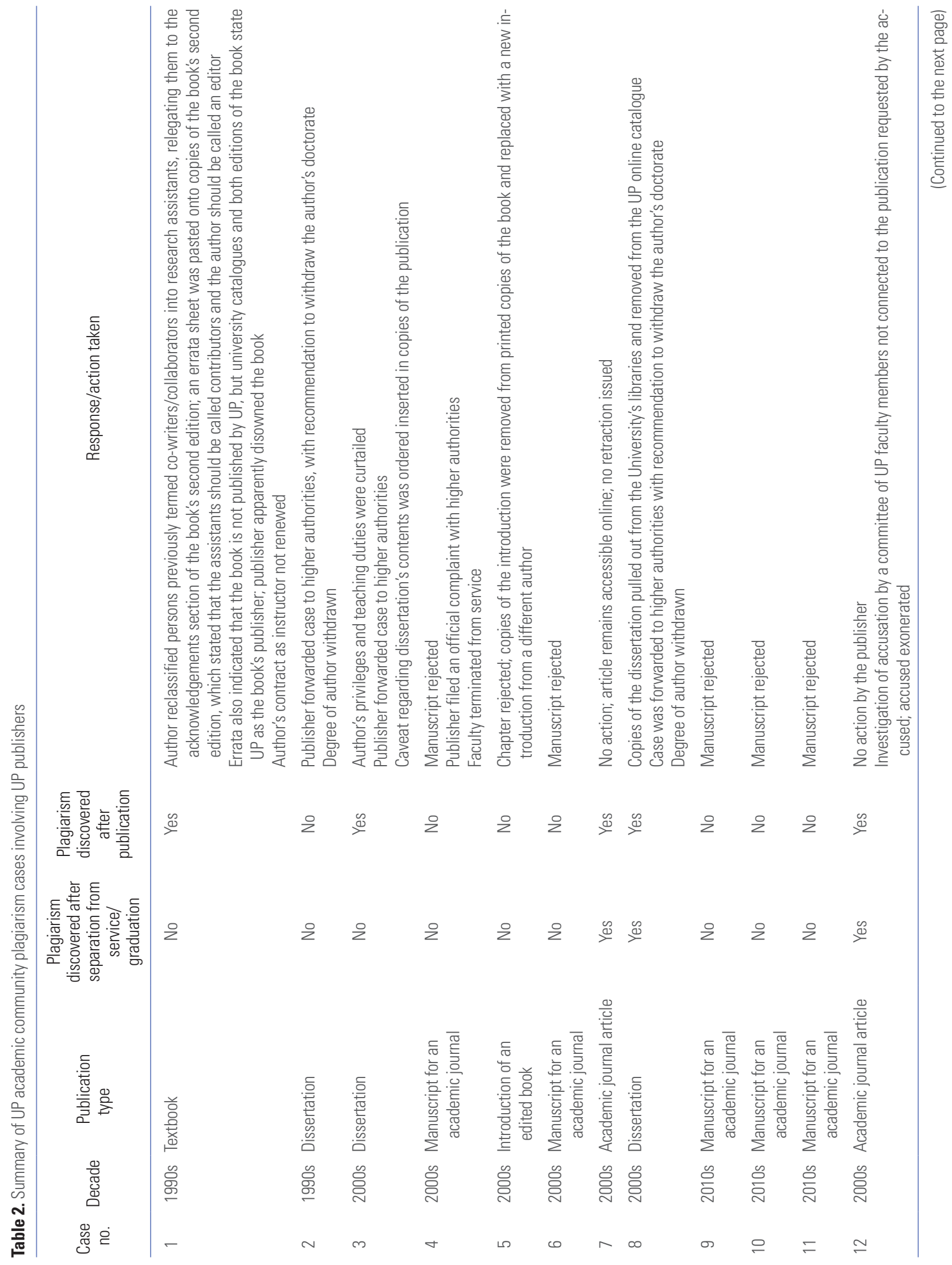




\section{science editing}




sources for Table 2 are a court decision [12], an issue of the UP Gazette [13], and a book [14].

In case 12, which ended in exoneration, the accused had already voluntarily separated from UP because of career advancement well before her case was investigated. Cases 5 and
7 involve the same person, who had previously been scheduled for termination due to another dishonesty issue. Thus, these cases are excluded from Table 3, which shows how the specific responses to plagiarism by publishers within UP and in other institutions are related to the academic careers of the

Table 3. Plagiarism response/response result and academic careers of UP faculty members and students

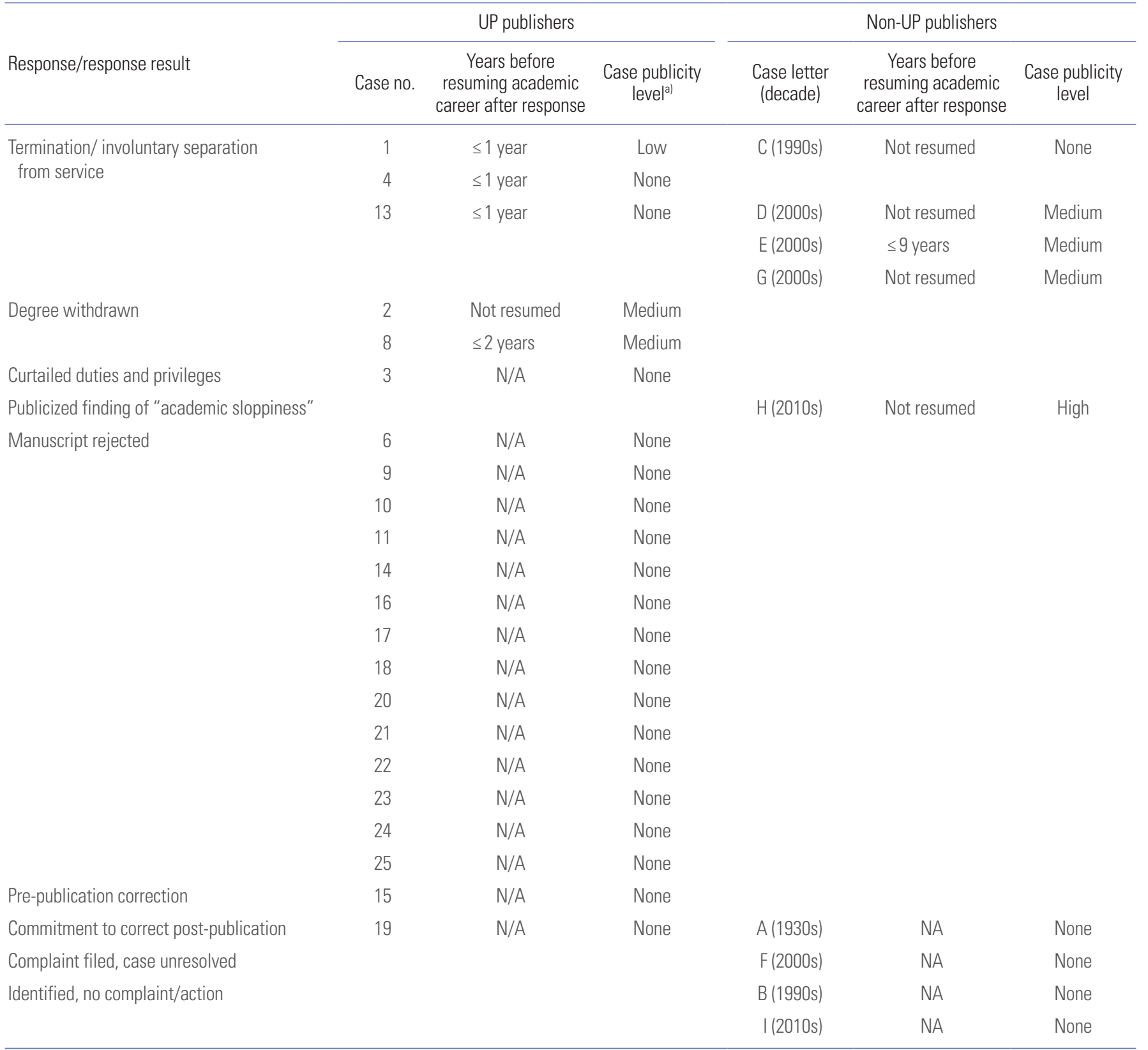

UP, University of the Philippines; NA, not applicable.

a)Gradations: 1) None (absolutely confidential cases; only parties involved and concerned university officials were privy to the case details); 2) Low (details of the case can be found at most in one print publication with limited distribution); 3) Medium (details of the case could be viewed, at most, in 2 print and/or 1 online publication soon after the case's resolution); 4) High (details of the case easily obtainable, offline and online, appearing in various publications and having had mass media coverage while it was still pending or immediately after it was resolved). 
accused. The non-UP publisher cases are designated as cases A-I and arranged in approximate chronological order. Since we considered suspension or termination of academic career as the main effect, we gave a notation of "N/A" (not applicable) for cases wherein careers were never suspended or terminated because of a response to plagiarism. We also highlighted case publicity level. In terms of the relatively public cases (2, 8 , D, and G), most became public because the forums chosen for resolution needed decisions to be published, while details of two cases (E and $\mathrm{H}$ ) were leaked to the media. Besides the abovementioned sources for Table 2, the other sources for Table 3 are a book chapter [15], two UP Gazette issues [16,17], a news article [18], and the unpublished text of a presentation [19].

We will provide here as much contextualization as is allowed by the university's confidentiality rules. In case 1 , though the author's temporary faculty member appointment was not renewed, he was retained as a member of UP's nonteaching academic staff before becoming affiliated with other institutions. In case 4 and 13, the faculty member who resigned or was terminated continued to have an academic career outside UP, despite the seriousness of their offenses in terms of the quantity or contribution of plagiarized content in their work. In two related cases (8 and G), the sections with plagiarized content were so crucial to the purportedly new work that doubt was cast on the originality of their projects. The author in case 8 was nevertheless able to return to teaching outside UP after about 2 years, while case G's author con- tinues to work in a field related to his discipline. The author in case $\mathrm{D}$ has followed a track similar to that in case $\mathrm{G}$.

Although the authors in case 2 and case $C$ ceased to be connected to the academe because of plagiarism, they were able to have scholarly work published and deposited in university libraries. Other scholars have cited the post-academe publications of both more than once. Meanwhile, case H's author was effectively promoted to a position wherein he is directly involved in the production of texts that are among the main objects of analysis in his discipline. Lastly, even the author in cases 5 and 7 has been able to pursue a career in publishing outside of the Philippines.

\section{Discussion}

As stated in our introduction, the thrust of these responses to plagiarism was assumed to be punitive rather than rehabilitative, even if a relatively lenient response was executed most of the time. This assumption was based on our previous findings examining the university's rules on plagiarism [20], which are summarized in Table 4.

Especially at UP Diliman, there only recently has been a turn from the punitive/legalistic to the corrective/academicethical regarding policies on plagiarism for UP's faculty and students. However, as our data shows, the absence of clear guidelines has left responses to plagiarism-from harsh penalties to no punishment at all-entirely within the discretion of UP publishers.

Table 4. Main rules and regulations on plagiarism for UP students and faculty members

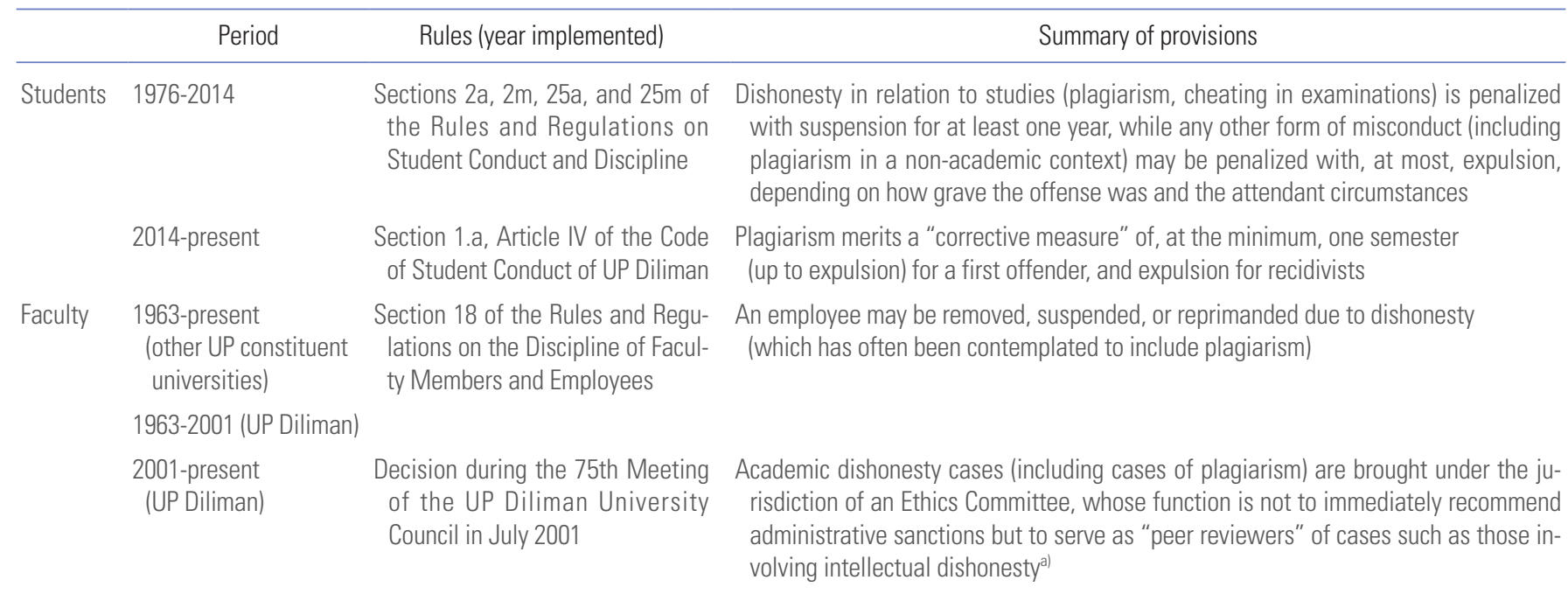

UP, University of the Philippines.

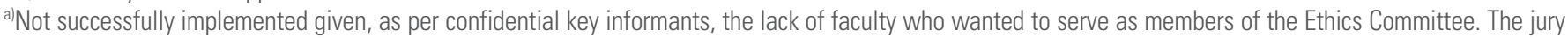
system (no standing committee, case-to-case committee members drawn from all full professors) was implemented by the UP Board of Regents on 27 October 2011. 
Besides this arbitrariness, the data also reveals that a plagiarism charge and/or penalty does not necessarily mean that credibility becomes widely questioned. One possible explanation is that most of those charged and proven to have committed plagiarism in these cases may have been able to rely on the mitigating circumstance of being a first-time/one-time offender. Besides such circumstances, the rarely breached university rules on confidentiality almost always ensure that the careers of members of UP's academic community remain undisturbed by a UP publisher finding plagiarism in their work. These very rules keep us from thoroughly discussing response appropriateness (type, severity) in relation to the extent of plagiarism committed.

As previously noted, we wanted to examine how UP publishers deal with the need to keep the reputation/integrity of their institution intact while also fulfilling their gatekeeping functions. Strict confidentiality allows publishers to dispose of plagiarism-laden submissions without getting a reputation for being overly strict or hostile to authors and, in the case of the "internal affairs" discussed here, to maintain a veneer of high academic standards for the university to which they are attached. Confidentiality, however, does not help publishers fulfill their responsibility to keep the fruits of dishonesty from being published. If only the author is informed of his or her plagiarism, it cannot be guaranteed that such a breach in proper scholarship is corrected; work with serious plagiarism issues may still be disseminated and referenced by other scholars. Indeed, of the 25 cases involving UP publishers and the nine cases involving non-UP publishers tackled here, most, if not all, of the works that were proven to be plagiarized after publication remain accessible in at least one library; save in one case, promises to correct disseminated publications were not known to have been carried out. At least one of the manuscripts that was rejected after submission was later published by another journal, with problematic sections still unaddressed.

To address response arbitrariness and the ill effects of strict confidentiality - and perhaps to serve as a deterrent against submitting plagiarized manuscripts - we recommend that 1) all UP publishers write down and publicize clear guidelines on how they will deal with plagiarism, including rules on retraction; 2) UP publishers require a paper submission provenance detailing where the work was previously submitted, why it was withdrawn or rejected, and, if the rejection was due to plagiarism, what the publisher's findings were and how they were addressed; 3) a list of those discovered to have committed plagiarism-along with the findings of the editor(s) who assessed their work and the penalties given, if any-is made accessible to the community of UP publishers and, ideally, all academic publishers who want information on sub- mitting authors; and 4) a body is established to manage the aforementioned list and monitor if penalties or corrective measures are implemented.

\section{Conflict of Interest}

No potential conflict of interest relevant to this article was reported.

\section{Acknowledgments}

We acknowledge the Office of the Chancellor of the University of the Philippines Diliman, through the Office of the Vice Chancellor for Research and Development, for funding support via the Source of Solutions Grants to the project entitled "The UP Diliman handbook on academic and authorial integrity." Funding was also provided by the Office of the Vice President for Academic Affairs, University of the Philippines, for the project entitled "Dishonesty and disgrace: a history of University of the Philippines' responses to alleged acts of plagiarism committed by members of its faculty, 1908-2010." We also acknowledge the research assistance of Allan Mark Rimban, Raya Mae Manalo, Farida Bianca Velicaria, Enrico Gloria, Ferth Vandensteen Manaysay, Jonathan Victor Baldoza, Giselle Joyce Nadine de la Peña, Judith Camille Rosette, and Jesa Kara Gascon.

\section{References}

1. Wellington J, Nixon J. Shaping the field: the role of academic journal editors in the construction of education as a field of study. Br J Sociol Educ 2005;26:643-55. https://doi. org/10.1080/01425690500293835

2. Philippine Journal of Social Development. Editorial and publication policies [Internet]. Quezon City: College of Social Welfare and Community Development, University of the Philippines Diliman; 2016 [cited 2019 Jun 18]. Available from: http://cswcd.upd.edu.ph/wp-content/uploads/2018/04/PJSD-Editorial-and-Publication-Policies-112816.pdf

3. Office of the Vice Chancellor for Research and Development, University of the Philippines Diliman. Journal policy on research misconduct [Internet]. Quezon City: Office of the Vice Chancellor for Research and Development, University of the Philippines Diliman; 2009 [cited 2019 Jun 18]. Available from: http://journals.upd.edu.ph/index. php/humanitiesdiliman/article/view/6692/5797

4. Asian Studies Editorial Staff. Turning the page: re-examining standards in academic journal publication. Asian Stud 2014;50:99-112. 
5. Obille KL. Can information literacy develop intellectual honesty? J Philipp Librariansh 2013;33:47-57.

6. Stern S. Copyright originality and judicial originality. Univ Tor Law J 2013;63:385-417. https://doi.org/10.3138/ utlj.63.3.231112

7. Sagun KK, Luyt B. Fulfilling the cultural without forsaking the commercial: university presses in the Philippines from the perspective of three directors. J Sch Publ 2016;47:25066. https://doi.org/10.3138/jsp.47.3.250

8. Tecson-Mendoza EM. Scientific and academic journals in the Philippines: status and challenges. Sci Ed 2015;2:73-8. https://doi.org/10.6087/kcse.47

9. Janairo JI. Reviving a scientific journal: challenges and strategies. Sci Ed 2018;5:59-61. https://doi.org/10.6087/kcse.120

10. University of the Philippines Diliman. 2012 Code of student conduct of UP Diliman [Internet]. Quezon City: University of the Philippines Diliman [cited 2019 Jun 18]. Available from: https://osu.up.edu.ph/wp-content/uploads/2015/09/2012Code-of-Student-Conduct.pdf

11. University of the Philippines Diliman. Faculty manual. Quezon City: University of the Philippines Diliman; 2003.

12. Supreme Court of the Philippines. G.R. No. 134625 (Aug 31, 1999).

13. Office of the Secretary of the University, University of the Philippines. Withdrawal of the $\mathrm{PhD}$ degree which was conferred on Mr. Serafin F. Delica on 27 April 2008. UP
Gaz 2011;42:57-8.

14. Vitug MD. Hour before dawn: the fall and uncertain rise of the Philippine supreme court. Quezon City: Cleverheads Publishing; 2012.

15. Salamanca BS. Bocobo fosters a vibrant nationalism: reassertion of Filipino values as an underlying concept in academic life. In: Alfonso OM, editor. University of the Philippines: the first 75 years (1908-1983). Quezon City: University of the Philippines Press; 1985. p. 201-57.

16. Office of the Secretary of the University, University of the Philippines. On the case of Prof. Lourdes G. Redoloza. UP Gaz 2000;31:9.

17. Office of the Secretary of the University, University of the Philippines. Report of the ad hoc committee tasked to determine the possible academic failings of Professor Marvic MVF Leonen. UP Gaz 2011;42:78.

18. Ramos LC. UP Cebu prof accused of copying loses job. Sun. Star Cebu. 2006 Jun 28;Sect. A:2.

19. Librero L. Plagiarism: an intellectual leprosy. Talk presented at: 11th Talakayan Series for Environment and Development; 2011 Jan 13; Los Banos, Laguna, Philippines.

20. Reyes MP, Ariate JF. Final research report on academic and authorial integrity in University of the PhilippinesDiliman. Unpublished report. Quezon City: University of the Philippines Diliman; 2014. 